\title{
Complications of fluid overload during hysteroscopic surgery: cardiomyopathy and epistaxis - A case report -
}

Received April 25, 2019

Revised 1st, July 12, 2019

2nd, August 7, 2019

Accepted September 10, 2019

\section{Corresponding author}

Kwang Ho Lee, M.D., Ph.D. Department of Anesthesiology and Pain Medicine, Wonju Severance Christian Hospital, 20 Ilsan-ro, Wonju 26426, Korea

Tel: 82-33-741-1526

Fax: 82-33-742-8198

E-mail: khlee6006@yonsei.ac.kr

\section{ORCID}

https://orcid.org/0000-0002-1641-1301

\section{Eun Bi Lee, Jihyoung Park, Hyun Kyo Lim, Yong II Kim, Yeonghyeon Jin, and Kwang Ho Lee}

Department of Anesthesiology and Pain Medicine, Yonsei University Wonju College of Medicine, Wonju, Korea

Background: Hysteroscopic surgery has been used in various gynecological fields. However, massive fluid overload can occur as a complication due to persistent infusion of media for uterine cavity distension. We present the case of a woman who developed cardiomyopathy with pulmonary edema and epistaxis during hysteroscopic surgery.

Case: A 76-year-old female underwent hysteroscopic septectomy. She manifested abrupt, active nasal bleeding and regurgitation in the intravenous line. Heart rate, $\mathrm{SpO}_{2}$, and $\mathrm{PETCO}_{2}$ decreased from 55 beats/min to 29 beats/min, from 100\% to 56\%, and from $31 \mathrm{mmHg}$ to $9 \mathrm{mmHg}$, respectively. After the operation, brain CT showed bilateral prominent superior ophthalmic vein dilation. Echocardiography showed left ventricle apical ballooning and global hypokinesia. The patient recovered after two days of conservative management, with no sequelae.

Conclusions: Although hysteroscopic surgery is a simple procedure, careful monitoring is necessary to prevent complications from absorption of fluid distending media during the procedure.

Keywords: Cardiomyopathy; Epistaxis; Hysteroscopy; Pulmonary edema.
Hysteroscopic surgery is widely used for treatment of gynecological diseases, such as septae, synechiae, and intrauterine myoma. Advantages include less invasiveness and faster recovery compared to traditional laparotomy. It is reported that the incidence of complication is about $0.22 \%$ [1]. Known complications include uterine perforation, massive bleeding, and fluid overload [1]. Fluid overload can occur because of continuous infusion of fluid media for distending the uterus and can be accompanied by severe complications, such as pulmonary edema, hyponatremia, hypo-osmolarity, and cerebral edema. If such complications are not recognized, pulmonary edema and cardiovascular collapse may also oc- cur and can lead to catastrophic outcomes [2]. Direct media absorption through an exposed vessel or sinus during surgery is the main cause of fluid overload [3]. However, it is uncommon to report cardiomyopathy as well as pulmonary edema due to fluid overload. Herein, we report a case of severe bradycardia, pulmonary edema, cardiomyopathy, and epistaxis with extreme hyponatremia during hysteroscopic surgery.

\section{CASE REPORT}

This case report was approved by the Wonju Severance Christian Hospital Institutional Review Board (IRB). The IRB

This is an Open Access article distributed under the terms of the Creative Commons Attribution Non-Commercial License (http://creativecommons.org/licenses/by-nc/4.0) which permits unrestricted non-commercial use, distribution, and reproduction in any medium, provided the original work is properly cited.

Copyright (c) the Korean Society of Anesthesiologists, 2020 
approval number is CR319331.

A 76-year-old female patient, $149 \mathrm{~cm}$ in height and $62 \mathrm{~kg}$ in weight, was scheduled for laparoscopic surgery on a calcified mass, $3.1 \mathrm{~cm}$ in size, located on the rectovesical pouch. She was also scheduled for a hysteroscopy due to intrauterine septae.

The patient had a medical history of diabetes mellitus and hyperthyroidism. Upon arrival in the operating room, blood pressure was 162/61 $\mathrm{mmHg}$, heart rate was 75 beats/min, and $\mathrm{SpO}_{2}$ was $99 \%$. Anesthesia was induced with propofol $100 \mathrm{mg}$ and rocuronium $50 \mathrm{mg}$. After tracheal intubation, anesthesia was maintained with an oxygen-air-desflurane mixture and a remifentanil infusion.

Laparoscopic myomectomy was performed for $15 \mathrm{~min}$ at about $15^{\circ}$ in the Trendelenburg position. Subsequently, the patient's posture was changed to the lithotomy position, and hysteroscopy was performed. Hysteroscopy-guided septectomy was carried out with a monopolar instrument. The distending fluid media was infused with an inflated pressure cuff registered at a pressure of $100 \mathrm{mmHg}$.

Fifty minutes after hysteroscopic surgery, the pulse rate of the patient suddenly decreased from $50-60$ beats/min to 29 beats/min. Peak airway pressure increased from $19 \mathrm{mmHg}$ to $35 \mathrm{mmHg}$. $\mathrm{SpO}_{2}$ decreased gradually from $100 \%$ to $85 \%$ and then to $56 \%$ over the span of 20 min. PETCO $_{2}$ decreased from $31 \mathrm{mmHg}$ to $16 \mathrm{mmHg}$ and then to $9 \mathrm{mmHg}$. Blood pressure was maintained at 90-105/60-70 mmHg. We changed the oxygen concentration of the ventilator from 0.5 to 1.0. The pulse rate was recovered to 60 beats/min after intravenous atropine $0.5 \mathrm{mg}$ injection. Non-invasive blood pressure was maintained at the pre-event status, so we did not inject any inotropic agents. A pink and frothy secretion was observed upon tracheal suction. Spontaneous nasal bleeding in both nostrils, whole-face congestion, and IV line regurgitation in the left arm occurred. We immediately informed the surgeon and recommended that the surgery be concluded early. The left radial artery was catheterized for blood sampling and blood pressure monitoring. A central venous catheter was inserted at the right internal jugular vein via blind Seldinger technique. Central venous pressure was not measured. Arterial blood gas analysis showed pH 7.12, $\mathrm{PCO}_{2} 50 \mathrm{mmHg}, \mathrm{PO}_{2}$ $65 \mathrm{mmHg}, \mathrm{HCO}_{3}{ }^{-} 16.3 \mathrm{mM}$, and $\mathrm{FiO}_{2}$ 1.0. Serum sodium and potassium levels were $117 \mathrm{mEq} / \mathrm{L}$ and $2.5 \mathrm{mEq} / \mathrm{L}$, respectively. Forty minutes after the event, $\mathrm{SpO}_{2}$ was $90 \%$, and $\mathrm{PETCO}_{2}$ was $15 \mathrm{mmHg}$.

For hysteroscopy, 6,000 ml of Urosol ${ }^{\circledR}$ solution (a mixture of $2.7 \%$ sorbitol and $0.54 \%$ mannitol) was used. At the end of the operation, the drainage quantity of the distending media comprised about 4,000 ml, but the exact amount was not confirmed. Total anesthetic time was $160 \mathrm{~min}$. During the first hour, $200 \mathrm{ml}$ of Ringer's solution was infused, and urine output was $100 \mathrm{ml}$. During the second hour and the subsequent $40 \mathrm{~min}, 200 \mathrm{ml}$ and $350 \mathrm{ml}$ of Ringer's solution was infused, and urine output was $1,000 \mathrm{ml}$ and $600 \mathrm{ml}$ without diuretics, respectively.

The patient was transferred to the intensive care unit (ICU) without tracheal extubation after chest and brain computed tomography (CT) scans. Chest CT showed pulmonary edema and acute respiratory distress syndrome (Fig. 1). Brain CT showed bilateral prominent superior ophthalmic vein dilation (Fig. 2). No intracranial hemorrhage or brain swelling occurred. CT pulmonary angiography and CT lower extremity venography was performed and showed no evidence of thromboembolism. Echocardiography performed $6 \mathrm{~h}$ after the event showed proper contractility and no dilation of the right ventricle but left ventricle apical ballooning, global hypokinesia of the mid to apical segments, and akinesia of the interventricular septum from the mid to apical segments (Fig. 3). Postoperative 12-lead electrocardiogram (ECG) revealed sinus tachycardia of 109 beats/min without ST-segment or T wave abnormality. Serum troponin I and CK-MB were 0.082

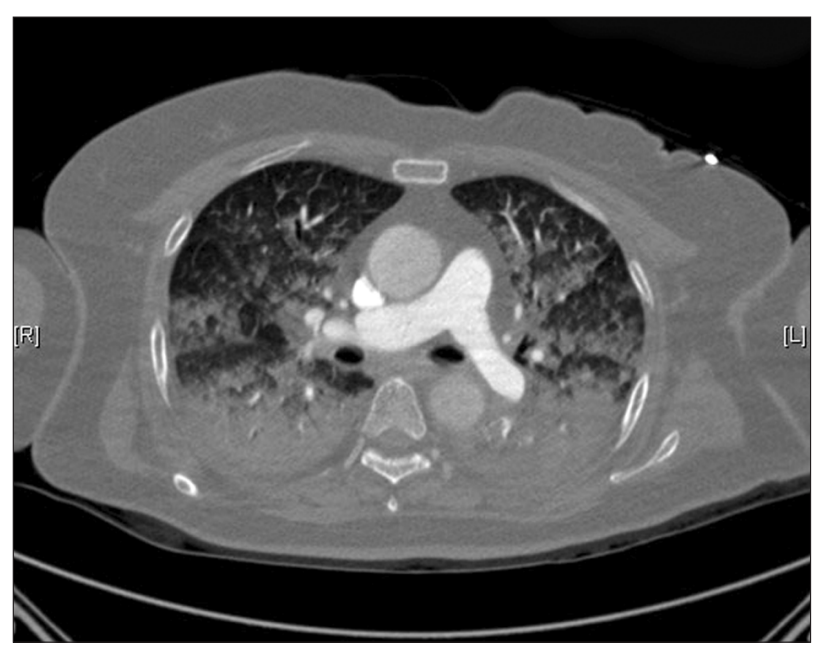

Fig. 1. Chest computed tomography shows dependent consolidation, ground glass opacity, and interlobular septal thickening in both lungs. Probable pulmonary edema or acute respiratory distress syndrome. 


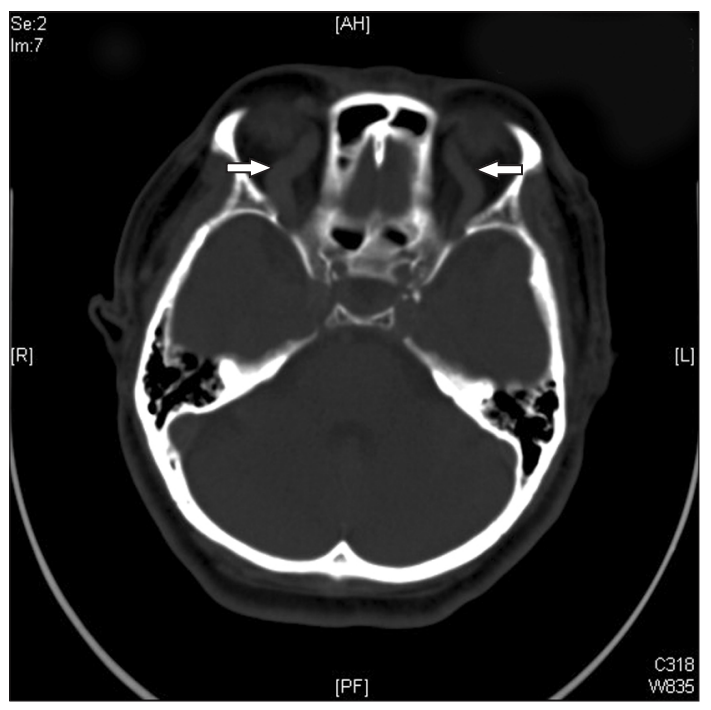

Fig. 2. Brain computed tomography. Superior ophthalmic vein was severely dilated (arrows), and no intracranial hemorrhage was found.

$\mathrm{ng} / \mathrm{ml}$ and $3.0 \mathrm{ng} / \mathrm{ml}$, respectively. Urine output was $1,780 \mathrm{ml}$ without diuretics during the first five hours after entering the ICU.

On the first postoperative day, ECG revealed sinus tachycardia (120 beats/min) with nonspecific T wave abnormality. The serum sodium level was $127 \mathrm{mEq} / \mathrm{L}$, potassium level was $3.9 \mathrm{mEq} / \mathrm{L}$, and cardiac biomarkers were elevated with troponin I of $9.28 \mathrm{ng} / \mathrm{ml}$ (normal $\leq 0.046 \mathrm{ng} / \mathrm{ml}$ ) and CK-MB of $18.54 \mathrm{ng} / \mathrm{ml}$ (normal $\leq 3.7 \mathrm{ng} / \mathrm{ml}$ ). Follow-up echocardiography showed continued regional wall motion abnormality (RWMA), but the severity was decreased. On the second postoperative day, the anteroposterior chest radiograph (chest AP) showed improved pulmonary edema. Arterial blood gas analysis showed $\mathrm{pH}$ 7.46, $\mathrm{PCO}_{2} 30 \mathrm{mmHg}, \mathrm{PO}_{2} 183 \mathrm{mmHg}$, $\mathrm{HCO}_{3}^{-} 21 \mathrm{mM}$, and $\mathrm{FiO}_{2}$ 0.3. The patient's serum sodium level was $143 \mathrm{mEq} / \mathrm{L}$, potassium level was $3.6 \mathrm{mEq} / \mathrm{L}$, and cardiac biomarkers returned to normal ranges. Extubation was performed, and the patient was transferred to the general ward. On the fifth postoperative day, the patient was discharged without any sequelae. At one week after discharge, echocardiography showed normal myocardial systolic function.

\section{DISCUSSION}

Complications can occur due to fluid overload during hysteroscopic surgery. Among the various reasons, direct media absorption through an exposed vessel or sinus during surgery

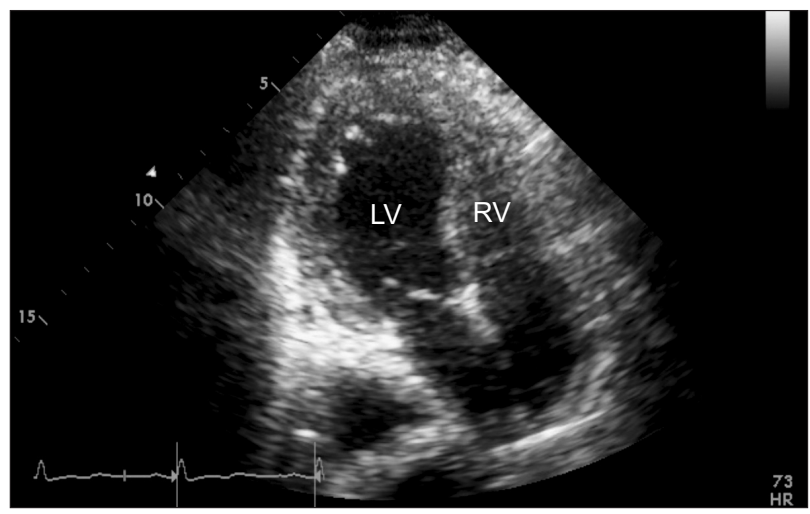

Fig. 3. Transthoracic echocardiographic apical 4-chamber view (endsystolic phase) findings in intensive care unit after hysteroscopic surgery. Left ventriclar dilation and global hypokinesia were observed. LV: left ventricle, RV: right ventricle.

is the main cause of fluid overload [3]. When hypotonic electrolyte-free fluid is used, hypervolemia, hyponatremia, and hypo-osmolality can occur. With Urosol ${ }^{\circledR}$ solution (a mixture of $2.7 \%$ sorbitol and $0.54 \%$ mannitol), metabolism of sorbitol may occur up to metabolic acidosis.

Severe hyponatremia can produce various neurological symptoms [4]. In this case, even in severe hyponatremia, neurological symptoms, such as nausea, headache, and seizure, were not found because the patient was under general anesthesia. Hence, fluid overload and hyponatremia went undetected until pulmonary edema developed.

We first suspected pulmonary thromboembolism and right heart failure based on the clinical features of sudden bradycardia, neck vein dilation, active nasal bleeding, and IV line regurgitation. However, CT pulmonary angiography and chest CT showed no evidence of pulmonary artery embolism, and CT lower extremity venography showed no deep vein thrombus.

According to Istre et al. [5], when 1,000 $\mathrm{ml}$ of fluid is absorbed, plasma sodium is reduced by $10 \mathrm{mEq} / \mathrm{L}$. In the operating room, the plasma sodium level was $117 \mathrm{mEq} / \mathrm{L}$. Therefore, this patient can be assumed to have absorbed 2.5 $\mathrm{L}$ of distending media. Consequently, it is reasonable to believe that severe water absorption caused pulmonary edema. The right heart failure thought to be accompanied by this was likely due to an increase in pulmonary vascular resistance caused by hypoxic pulmonary vascular constriction and a catecholamine surge caused by sudden pulmonary edema [6]. 
Urine output during the operation and the five postoperative hours was 1,700 $\mathrm{ml}$ and 1,780 $\mathrm{ml}$, respectively. Spontaneous recovery of right ventricular function was thought to be associated with rapid recovery of intracardiac blood volume due to increased urine volume. This was confirmed by bedside echocardiography, which was performed about six hours after the event, showing both proper contractility and no dilation of the right ventricle. However, echocardiography showed left ventricle apical ballooning, global hypokinesia of the mid to apical segments, and akinesia of the interventricular septum from the mid to apical segments. Postoperative electrocardiography showed sinus tachycardia of 109 beats/ min and no other abnormalities. Cardiac biomarkers were slightly elevated, with troponin I of $9.28 \mathrm{ng} / \mathrm{ml}$ (normal $\leq 0.046$ $\mathrm{ng} / \mathrm{ml}$ ) and CK-MB of $18.54 \mathrm{ng} / \mathrm{ml}$ (normal $\leq 3.7 \mathrm{ng} / \mathrm{ml}$ ).

The first postoperative day, follow-up echocardiography showed improved left ventricular RWMA. The second postoperative day, cardiac biomarkers returned to normal ranges. At one week postoperatively, echocardiography showed diminishing RWMA and normal global left ventricular systolic function. Based on the patient's clinical features and echocardiography results, we suspect a diagnosis of Takotsubo cardiomyopathy. The pathophysiology is not well established, but catecholamines are thought to play an important role in inducing Takotsubo cardiomyopathy.

Some cases have been reported in which severe hyponatremia is associated with Takotsubo cardiomyopathy $[7,8]$. It is thought that excessive catecholamines are released secondary to abnormal central nervous system function. This elevated level of catecholamines has the potential to injure myocytes directly or indirectly, inducing multi-vessel coronary spasm [7]. According to Kolar et al. [9], in the hyponatremia state, intracellular calcium overload may occur due to impaired function of myocyte membrane sodium-calcium pumps.

Catecholamine level, such as those of epinephrine and norepinephrine, was not measured in this patient. Therefore, we cannot verify the specific mechanism of cardiac dysfunction in. She had no previous cardiac-related symptoms. Coronary angiography was not performed due to medical cost. Absence of coronary angiography is a major challenge in diagnosis of Takotsubo cardiomyopathy. Nevertheless, we concluded Takotsubo cardiomyopathy triggered by severe hyponatremia based on clinical features and echocardiography findings. In this case, therefore, we conclude that Takotsubo cardiomyopathy exacerbated pulmonary edema induced by volume overload and venous congestion, resulting in decreased pulmonary function and epistaxis.

In summary, hysteroscopic surgery is less complex than laparotomy. However, serious complications, such as fluid overload and cardiomyopathy, can occur during the procedure. Therefore, anesthesiologists and surgeons should pay close attention to variables such as saturation, capnography, and distending media volume during hysteroscopic surgeries.

\section{CONFLICTS OF INTEREST}

No potential conflict of interest relevant to this article was reported.

\section{ORCID}

Eun Bi Lee, https://orcid.org/0000-0001-6409-0795

Jihyoung Park, https://orcid.org/0000-0003-1320-411X

Hyun Kyo Lim, https://orcid.org/0000-0003-4812-1728

Yong Il Kim, https://orcid.org/0000-0003-4260-8324

Yeonghyeon Jin, https://orcid.org/0000-0002-9031-2950

\section{REFERENCES}

1. Aydeniz B, Gruber IV, Schauf B, Kurek R, Meyer A, Wallwiener D. A multicenter survey of complications associated with 21,676 operative hysteroscopies. Eur J Obstet Gynecol Reprod Biol 2002; 104: $160-4$

2. Bradley LD. Complications in hysteroscopy: prevention, treatment and legal risk. Curr Opin Obstet Gynecol 2002; 14: 409-15.

3. AAGL Advancing Minimally Invasive Gynecology Worldwide, Munro MG, Storz K, Abbott JA, Falcone T, Jacobs VR, et al. AAGL practice report: practice guidelines for the management of hysteroscopic distending media: (replaces hysteroscopic fluid monitoring guidelines. J Am Assoc Gynecol Laparosc. 2000;7:167168.). J Minim Invasive Gynecol 2013; 20: 137-48.

4. Riggs JE. Neurologic manifestations of fluid and electrolyte disturbances. Neurol Clin 1989; 7: 509-23.

5. Istre O, Bjoennes J, Naess R, Hornbaek K, Forman A. Postoperative cerebral oedema after transcervical endometrial resection and uterine irrigation with 1.5\% glycine. Lancet 1994; 344: 11879. 
6. Greyson CR. The right ventricle and pulmonary circulation: basic concepts. Rev Esp Cardiol 2010; 63: 81-95.

7. AbouEzzeddine O, Prasad A. Apical ballooning syndrome precipitated by hyponatremia. Int J Cardiol 2010; 145: e26-9.

8. Kawano H, Matsumoto Y, Arakawa S, Hayano M, Fijisawa H. Takotsubo cardiomyopathy in a patient with severe hyponatremia associated with syndrome of inappropriate antidiuretic hormone. Intern Med 2011; 50: 727-32.

9. Kolar F, Cole WC, Ostadal B, Dhalla NS. Transient inotropic effects of low extracellular sodium in perfused rat heart. Am J Physiol 1990; 259: H712-9. 